\title{
Increased Levels of Serum Glycosylated Hemoglobin are Associated with Depressive Symptoms in a Population with Cancer ( $\geq 49$ Years): An Antidepressant-Stratified Analysis [Retraction]
}

\author{
Huang $\mathrm{Y}, \mathrm{Xu} \mathrm{Y}, \mathrm{Liu}$ A. Clin Interv Aging. \\ 2021;16:205-212.
}

The Editor-in-chief and Publisher of Clinical Interventions in Aging wish to retract the published paper. A review by The Irish Longitudinal Study on Ageing (TILDA) investigation team found it was not possible to replicate the numbers reported in the article and raised concerns the authors had inaccurately interpreted the data. Some of these concerns are specified below.

- The participant flow chart within the manuscript (Figure 1), is reported inaccurately citing " 8054 " participants rather than "8504" participants. All subsequent figures and analyses appear to have been reported to fit this initial error, leaving these figures and analyses inaccurate throughout the rest of the article.

- Within the paper's title, and throughout the article " $>49$ years", or " $\geq 50$ years" should have been used when referring to the sample's age, rather than " $\geq 49$ years". In the publicly accessible dataset, it was not possible to determine the precise age of those aged $<50$ years, so participants specifically aged 49 couldn't have been included in these analyses.

- Descriptions on Page 206 indicate the authors did not fully understand the TILDA study design and methodology:

o "TILDA also approves applications for privileged access to the data set by a website called 'hot desk'." The hot desks are physical PCs located in Trinity College Dublin and St James's Hospital Dublin, not a website, and there is no remote access to non-public data.

○ "In summary, all subjects who have finished the self-completed questionnaire and computer-aided personal interview (CAPI) were invited to take a health examination in one of the health centres." The article referred to (Whelan and Savva, 2013) makes it clear that the option of a modified assessment in a participant's home was offered, which $10 \%$ of the study population took up.

○ "Technicians collected blood samples from all included subjects on the same day after they finished the self- completed questionnaire and the CAPI. The measurement procedures and methods of serum $\mathrm{GHb}$ levels in the cohort subjects were published elsewhere." This refers to Whelan and Savva (2013) which is the only paper involved in the design, conduct or direct analysis of TILDA data to which the authors refer. However, Whelan and Savva (2013) does not contain this information (it has no reference to methods for collection or measurement of blood samples), and the CAPI is not completed in the health assessment centre but in the home with a trained interviewer, while the SCQ is completed in the home privately and returned to TILDA by the participant.

The authors did respond to our queries and agreed that several errors relating to the collection and interpretation of data had been made. The authors wish to apologise for these errors and agree with the decision to retract the article.

Our decision-making was informed by our policy on publishing ethics and integrity and the COPE guidelines on retraction.

The retracted article will remain online to maintain the scholarly record, but it will be digitally watermarked on each page as "Retracted". 


\section{Publish your work in this journal}

Clinical Interventions in Aging is an international, peer-reviewed journal focusing on evidence-based reports on the value or lack thereof of treatments intended to prevent or delay the onset of maladaptive correlates of aging in human beings. This journal is indexed on PubMed Central, MedLine, CAS, Scopus and the Elsevier
Bibliographic databases. The manuscript management system is completely online and includes a very quick and fair peer-review system, which is all easy to use. Visit http://www.dovepress.com/ testimonials.php to read real quotes from published authors.

Submit your manuscript here: https://www.dovepress.com/clinical-interventions-in-aging-journal 